\title{
TRADISI RASULAN: NILAI PENDIDIKAN DARI KEARIFAN LOKAL DESA SELANG WONOSARI GUNUNGKIDUL
}

\author{
Frisma Mufti Hafisyah Dewanti, Muhammad Shaleh Assingkily, Izzatin Kamala \\ Universitas Islam Negeri Sunan Kalijaga Yogyakarta \\ frismamufti89@gmail.com, assingkily27@,gmail.com, \\ izaatinkamala@,gmail.com.
}

\begin{abstract}
Every harvest season arrives, the people of Selang Wonosari Village, Gunungkidul greet him with the apostolic tradition. The expression of gratitude that is entrenched in the tradition, has become the local wisdom of the region with its elemental value. This paper aims to examine the educational value of local wisdom in the village of Selang Wonosari Gunungkidul. In the discussion, it will be explained how the implementation of the Rasulan tradition in Selang Village, Wonosari District, Gunungkidul Regency, what are the contents of the educational values contained in the Rasulan tradition and how these values are given. The study used a qualitative approach with the background of the activities of the Rasulan tradition in Selang Village. The results showed that in the Rasulan tradition there were activities in the hamlet cleaning, gunungan carving, slametan and performing arts. The Islamic values in the tradition broadly include the value of Islamic education and moral education. The value of aqidah education includes (1) fostering a sense of confidence in Allah. by giving thanks, (2) remembering Allah Almighty. through slametan in the form of prayer, tahlil and remembrance. While the value of moral education includes (1) the value of sincerity, (2) solidarity, friendship and harmony between citizens, (3) sharing through charity "earth" and food between citizens.
\end{abstract}

Keyword: Educational Values, Harvest, Rasulan Tradition.

\begin{abstract}
Abstrak
Setiap musim panen tiba, masyarakat Desa Selang Wonosari Gunungkidul menyambutnya dengan tradisi rasulan. Ungkapan syukur yang membudaya dalam tradisi tersebut, menjadi kearifan lokal daerah dengan kandungan unsur nilainya. Tulisan ini bertujuan mengkaji nilai pendidikan dari kearifan lokal Desa Selang Wonosari Gunungkidul. Dalam pembahasan akan diuraikan bagaimana pelaksanaan tradisi rasulan di Desa Selang Kecamatan Wonosari Kabupaten Gunungkidul, apa saja muatan nilai-nilai pendidikan yang terdapat pada tradisi rasulan dan bagaimana nilai-nilai tersebut diberikan. Penelitian menggunakan pendekatan kualitatif dengan latar kegiatan yaitu tradisi rasulan di Desa Selang. Hasil penelitian menunjukkan bahwa di dalam tradisi rasulan terdapat kegiatan bersih dusun, kirab gunungan, slametan dan pentas seni. Adapun nilai-nilai keislaman dalam tradisi tersebut secara garis besar meliputi nilai pendidikan akidah dan pendidikan akhlak. Nilai pendidikan akidah mencakup (1) memupuk
\end{abstract}


rasa keyakinan kepada Allah swt. dengan mengucap rasa syukur, (2) mengingat Allah swt. melalui slametan berupa doa, tahlil dan zikir. Sedangkan nilai pendidikan akhlak mencakup (1) nilai keikhlasan, (2) solidaritas, silaturahmi dan keharmonisan antarwarga, (3) saling berbagi melalui sedekah "bumi" dan makanan antarwarga.

Kata kunci: Nilai Pendidikan, Panen, Tradisi Rasulan.

\section{A. Pendahuluan}

Budaya merupakan cara tepat dalam meminimalisir setiap perbedaan yang ada. Hal ini disebabkan nilai kebersamaan yang ditunjukkan dari setiap budaya, sehingga keragaman dipandang sebagai sesuatu yang unik, berwarna, bahkan menggairahkan, ketimbang mengedepankan unsur beda.

Keragaman yang ada menunjukkan kekayaan suatu daerah, wilayah, bahkan negara tertentu, sebut saja budaya Jawa yang terus lestari hingga saat ini di Indonesia. ${ }^{1}$ Kekayaan yang ditunjukkan melalui budaya juga dapat diakuisisi menjadi cerminan pribadi masyarakat Jawa pada umumnya.

Kajian terkait budaya Jawa meliputi bahasa, ${ }^{2}$ ritual budaya Jawa, ${ }^{3}$ seni, ${ }^{4}$ bahkan alat-alat tradisional ${ }^{5}$ khas Jawa telah banyak diteliti sebagai upaya

${ }^{1} \mathrm{Ni}$ Wayan Sartini, "Menggali Nilai Kearifan Lokal Budaya Jawa Lewat Ungkapan (Bebasan, Saloka, dan Paribasa)" Logat: Jurnal Ilmiah Bahasa dan Sastra 5 (1), 2009: 28-37. http://www.academia.edu/download/33900290/Bahasa_dan_Sastra_Logat_Vol_5_No_1_Apr il 2009.pdf\#page $=30$.

${ }^{2}$ Ucik Fuadhiyah, "Simbol dan Makna Kebangsaan dalam Lirik Lagu-lagu Dolanan di Jawa Tengah dan Implementasinya dalam Dunia Pendidikan" Lingua: Jurnal Bahasa dan Sastra 7 (1), 2011: 15-26. http://journal.unnes.ac.id/nju/index.php/lingua/article/download/865/798. Lihat Bea Anggraini, "Faktor-faktor Penanda Kesantunan Tuturan Imperatif dalam Bahasa Jawa Dialek Surabaya: Analisis Pragmatik" Humaniora 17 (1), 2012. 67-77. https://journal.ugm.ac.id/jurnalhumaniora/article/view/829.

${ }^{3}$ Sulkhan Chakim, "Potret Islam Sinkretisme: Praktik Ritual Kejawen?" Komunika: Jurnal Dakwah dan Komunikasi $3 \quad$ (1), 2015 : $1-9$. http://ejournal.iainpurwokerto.ac.id/index.php/komunika/article/view/110/84. Lihat Erviana Wulandari, "Penguatan Nilai Budi Pekerti Melalui Tradisi Rasulan Gunungkidul" Habitus: Jurnal Pendidikan, Sosiologi, dan Antropologi 2 (1), 2018: 139-150. https://jurnal.uns.ac.id/habitus/article/view/20416/15846.

${ }^{4}$ Didin Syarifuddin, "Nilai Wisata Budaya Seni Pertunjukan Saung Angklung Udjo Kota Bandung Jawa Barat Indonesia" Jurnal Manajemen dan Resort \& Leisure 13 (2), 2016. https://ejournal.upi.edu/index.php/jurel/article/view/4979.

5 Nurhadi Siswanto, "Metafisika Simbol Keris Jawa” Jurnal Filsafat 22 (1), 2012. https://journal.ugm.ac.id/wisdom/article/view/12986/9257. Lihat Kuntadi Wasi Darmojo, 
mengungkap makna dari realita atau fenomena yang ada selama ini secara ilmiah di kalangan akademisi.

Ritual budaya Jawa sebagai salah satu wujud "ekspresi” yang men-tradisi di masyarakat erat kaitannya dengan keyakinan agama yang dianut masyarakat Jawa, sebut saja tradisi rasulan dengan kandungan nilai pendidikan Islam $^{6}$ di dalam proses pelaksanaannya.

Adapun nilai-nilai yang menjadi hasil penelitian terdahulu meliputi nilai religius, ${ }^{7}$ budi pekerti, ${ }^{8}$ dan nilai sosial ${ }^{9}$ dalam tradisi rasulan. Tradisi rasulan merupakan kegiatan yang dilakukan oleh masyarakat Jawa pada umumnya saat musim panen tiba.

Kegiatan ini dipandang sebagai cara atau media untuk menyampaikan rasa syukur kepada Allah swt. karena telah memberikan hasil panen yang melimpah dan diharapkan terhindar dari segala musibah. Hal ini terus dilestarikan pula oleh masyarakat Jawa dan men-tradisi di Kabupaten Gunungkidul, di mana masyarakat setempat menyelenggarakan rasulan dengan melibatkan setiap elemen warga mulai dari kaula muda, anak-anak, dan orangtua di daerah tersebut.

Pada pelaksanaannya, setiap warga di daerah Gunungkidul mengkreasikan nilai-nilai pendidikan dalam budaya luhur rasulan melalui kombinasi era saat ini dengan tetap menjaga budaya setempat, seperti halnya mengadakan pentas seni dan lainnya.

"Eksistensi Keris Jawa dalam Kajian Budaya" Texture: Art \& Culture Journal 2 (1), 2019: 49-60. https://jurnal.isi-ska.ac.id/index.php/TXT/article/view/2630/2378.

${ }^{6}$ Muhammad Ridwan H, Muhammad Wardhan A, Nurkumala Rahmah, Hafidhoh Ma'rufah, Erny Dwi W, Haibat Hanafi R, Ayu Sri R.Y., Nurma Audina, Nurokhim, Umi Habibah, "Kajian Empiris Kuliah Kerja Nyata (KKN) UIN Sunan Kalijaga Terhadap Nilai Kearifan Lokal Tradisi Rasulan Gunungkidul” Prosiding Konferensi Pengabdian Masyarakat 1 (1), 2019: 113115. https://jurnal.uns.ac.id/habitus/article/view/20416/15846.

${ }^{7}$ Rinasari, “Aspek Pendidikan Nilai Religius dalam Tradisi Rasulan (Studi Kasus di Dukuh Ngadipiro Desa Grajegan Kecamatan Tawangsari Kabupaten Sukoharjo)" Skripsi (Solo: FKIP UMS, 2012). http://eprints.ums.ac.id/21066/14/11. Naskah Publikasi.pdf.

8 Erviana Wulandari, "Penguatan Nilai Budi Pekerti Melalui Tradisi Rasulan Gunungkidul" Habitus: Jurnal Pendidikan, Sosiologi, dan Antropologi 2 (1), 2018: 139-150. https://jurnal.uns.ac.id/habitus/article/view/20416/15846.

${ }^{9}$ Muhammad Isfironi, "Agama dan Solidaritas Sosial: Tafsir Antropologi Terhadap Tradisi Rasulan Masyarakat Gunungkidul DIY” Al-'Adalah 16 (2), 2013. http://ejournal.iainjember.ac.id/index.php/aladalah/article/view/162/138. 
Adapun prosesi kegiatan rutin tiap tahunnya tidak serta-merta menjadi "kewajiban" perangkat desa maupun dukuh (dusun), melainkan kerjasama antarwarga dengan mempercayakan kepanitiaan pelaksana setiap tahunnya. Bentuk kegiatan yang lazim dilaksanakan masyarakat Gunungkidul, khususnya Desa Selang Kecamatan Wonosari yakni bersih dusun, kirab gunungan, slametan dan pentas seni, di mana dalam pentas seni terdapat reog, wayang dan jathilan. ${ }^{10}$

Terdapatnya akulturasi budaya dan nilai ajaran Islam dalam tradisi rasulan ini menjadi daya tarik tersendiri untuk diteliti. Di mana kegiatan budaya yang lazimnya menyatukan antarwarga ternyata mengandung nilai-nilai pendidikan, keagamaan dan sosial secara bersamaan. Untuk itu, penulis tertarik mengkajinya dengan judul penelitian, "Tradisi Rasulan: Nilai Pendidikan dari Kearifan Lokal Desa Selang Kecamatan Wonosari Kabupaten Gunungkidul”.

\section{B. METODE}

Penelitian ini difokuskan pada penelitian ritual budaya masyarakat Kabupaten Gunungkidul, khususnya Desa Selang Kecamatan Wonosari sebagai ungkapan syukur atas limpahan hasil panen dan berharap terhindar dari musibah, yang dikenal dengan istilah rasulan. Untuk itu, penggunaan pendekatan penelitian kualitatif adalah cocok digunakan dalam mengungkapkan fakta-fakta sebagai kebenaran empiris dalam penelitian ini (field research).

Untuk mendapatkan data yang diperlukan berkenaan dengan fokus penelitian maka dilakukan observasi, wawancara, dan dokumentasi. Selanjutnya, analisis data dilakukan secara berkesinambungan dari awal sampai akhir penelitian, melalui teknik reduksi data, penyajian data, dan simpulan. Untuk menetapkan keabsahan (trustworthiness) data diperlukan teknik pemeriksaan yaitu Kredibilitas (credibility), keteralihan (transferability), ketergantungan (dependability), dan ketegasan (confirmability).

\footnotetext{
${ }^{10}$ Jathilan merupakan tarian "mirip" reog yang dipentaskan dalam tradisi rasulan di Desa Selang Kecamatan Wonosari Kabupaten Gunungkidul.
} 
Penelitian ini dilakukan dengan mengamati dan menganalisa nilai pendidikan bagi anak usia dasar yang terkandung dalam tradisi rasulan melalui dusun bersih, kirab gunungan, slametan dan pentas seni. Mencermati uraian di atas, secara sederhana kerangka alur metodologis riset ini dapat dilihat pada skema berikut. (Skema 1)

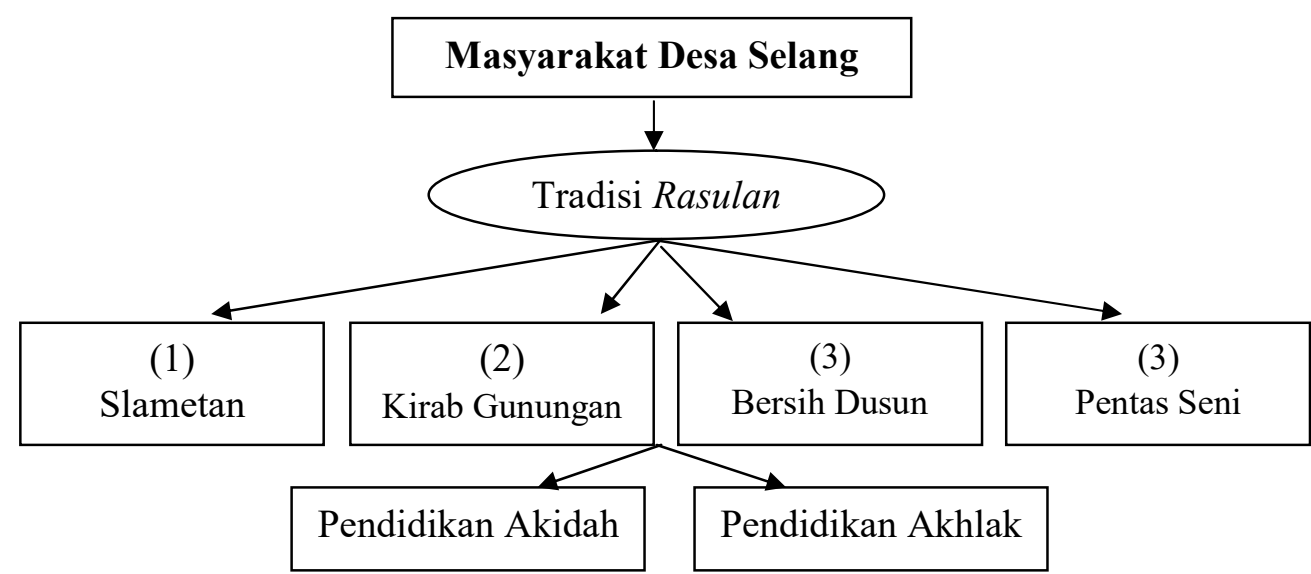

Skema 1. Alur Riset

\section{HASIL DAN PEMBAHASAN}

\section{Sejarah Tradisi Rasulan}

Tradisi rasulan merupakan ritual budaya yang dilaksanakan setiap tahun sekali oleh masyarakat Suku Jawa pada umumnya, termasuk masyarakat Suku Jawa yang mendiami Desa Selang Kecamatan Wonosari Kabupaten Gunungkidul D.I. Yogyakarta.

Menurut penuturan Kepala dukuh setempat di Desa Selang sendiri, bahwa tradisi rasulan ini sudah dilakukan secara turun-temurun oleh masyarakat, berikut kutipan wawancaranya:

"Tradisi rasulan sudah dilaksanakan oleh nenek moyang sejak zaman dahulu dan selalu dilaksanakan berdasarkan hari jawa minggu legi. Tradisi rasulan di selang ini bersifat turun temurun dan untuk melestarikan budaya Jawa, sebagai rasa syukur dan terimakasih 
kepada Allah ta'ala karena telah memberi hasil panen yang melimpah."11

Senada dengan itu, Bapak Karsino juga mengungkapkan bahwa, "tradisi rasulan dilaksanakan untuk melestarikan budaya jawa, budaya yang sudah diwarisi oleh nenek moyang."12 Setiap musim panen tiba, masyarakat secara bersama-sama menungkapkan rasa syukur mereka atas hasil yang melimpah melalui tradisi rasulan.

Tradisi rasulan sudah ada sejak zaman dahulu yang masih dilestarikan sampai sekarang oleh masyarakat Kabupaten Gunungkidul dari paling Timur yaitu Kecamatan Girisubo sampai ujung ujung Barat yaitu Kecamatan Panggang. Tradisi rasulan diperingati setiap sekali dalam satu tahun dengan hitungan menggunakan kalender Jawa.

Kegiatan yang dilaksanakan dalam setiap tahun tergantung kesepakatan warga masyarakat desa. Ada beberapa tradisi yang memang salalu ada atau wajib ada di setiap tahun. Kegiatan rasulan di Desa Selang dan masyarakat Kabupaten Gunungkidul umumnya saat ini dilakukan dengan membentuk kepanitiaan (melibatkan anak muda) yang merancang kegiatan agar seluruh elemen masyarakat ikut tergabung dan melestarikan budaya setempat sebagai suatu kearifan lokal. Sehingga kegiatan tersebut dapat dikreasikan dan berinovasi dengan esensi ungkapan syukur pada rezeki yang Allah swt. berikan.

\section{Tradisi Rasulan: Ritual Syukur Musim Panen Tiba}

Tradisi rasulan merupakan kegiatan yang dilakukan oleh masyarakat di Kabupaten Gunungkidul saat musim panen tiba. Kegiatan itu dilakukan oleh seluruh warga masyarakat Gunungkidul karena dianggap sebagai cara atau media untuk menyampaikan rasa syukur kepada Allah swt. atas hasil panen yang melimpah sekaligus berharap terhindar dari segala musibah.

11 Wawancara dengan Pak Joko Susilo (Kepala Dukuh Randukuning Desa Selang, Kecamatan Wonosari, Kabupaten Gunungkidul) pada tanggal 1 Desember 2019, pukul 10.50 WIB, di Balai Padukuhan.

12 Wawancara dengan Bapak Karsino, warga Desa Selang Wonosari Kabupaten Gunungkidul Yogyakarta, pada tanggal 2 November 2019, pukul 11.14 WIB, di rumah beliau. 
Masyarakat di Kabupaten Gunungkidul mayoritas beragama Islam, di Kabupaten Gunungkidul memiliki tradisi Rasulan yang di dalamnya terkandung beberapa muatan Islam kejawen yang dalam pelaksanaannya disesuaikan dengan ajaran Islam. ${ }^{13}$ Sehingga esensi bentuk wujud syukur kepada Allah tetap menjadi tujuan utama kegiatan.

Pelaksanaan kegiatan rasulan di Kabupaten Gunungkidul yaitu dengan membentuk pantia rasulan sejak 4 (bulan) sebelum hari pelaksanaan disepakati yang bertugas untuk menentukan susunan acara yang akan dilaksanakan pada puncak acara rasulan, teknis pelaksanaan acara, merencanakan waktu dan jumlah biaya yang dibutuhkan. Setelah menentukan teknis pelaksanaan, maka panitia memutuskan anggaran biaya yang akan dibebankan kepada warga masyarakat dihitung per kartu keluarga.

Hal ini senada dengan yang disampaikan Kepala Dukuh Randukuning berikut:

"Di Desa Selang persiapan rasulan di mulai sejak empat bulan sebelum hari $\mathrm{H}$ dengan menentukan panitia, tanggal, acara yang akan diselengarakan seperti apa serta acara-acara tambahan, tempat pelaksanaan, dan iuran yang dikeluarkan dengan musyaawarah. Di Desa Selang setiap KK (kepala keluarga) mengeluarkan sodaqoh dengan memberi ingkung. Hasil dari kenduri atau ingkung tadi dibagikan kepada para tamu undangan, pedagang dan masyarakat yang ada di sekitar secara adil. Acara lain seperti ketoprak, wayang kulit, reog, dan lain-lain, sebagai tambahan yang bertujuan untuk hiburan. Di Desa Selang sendiri, tradisi kirab budaya tidak selalu dilaksanakan karena tergantung hasil musyawarah atau kesepakatan warga sebelumnya. Tradisi yang selalu dilaksanakan oleh warga Desa Selang saat rasulan yaitu slametan atau kenduri." $"$

Lazimnya, kegiatan dalam tradisi rasulan terbagi menjadi dua, yakni acara wajib dan acara pelengkap. Kegiatan yang wajib terdiri dari bersih

\footnotetext{
${ }^{13}$ Marzuki, "Tradisi Dan Budaya Masyarakat Jawa Dalam Prespektif Islam” Makalah,

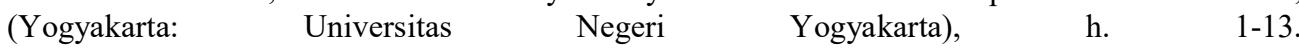
http://staffnew.uny.ac.id/upload/132001803/lainlain/Dr.+Marzuki,+M.Ag .+Tradisi+dan+Budaya +Masyarakat+Jawa+dalam+Perspektif+Islam.pdf.

14 Wawancara dengan Pak Joko Susilo (Kepala Dukuh Randukuning Desa Selang, Kecamatan Wonosari, Kabupaten Gunungkidul) pada tanggal 1 Desember 2019, pukul 10.50 WIB, di Balai Padukuhan.
} 
dusun, kirab gunungan ${ }^{15}$ dan slametan. Sedangkan pentas seni biasanya menjadi acara pelengkap pada acara puncak yang biasanya menampilkan pertunjukan wayang, reog dan jathilan.

Tradisi rasulan melalui empat kegiatan tersebut dilakukan dengan konsep menjalin kebersamaan antarwarga desa. Masyarakat akan gotongroyong dalam membersihkan desa tempat tinggalnya saat acara bersih dusun, di mana masyarakat saling membahu untuk membersihkan dusun masing-masing agar desa terlihat bersih. Di samping itu, warga juga didukung oleh pihak perangkat desa untuk memberikan hadiah pada dusun terbersih sebagai motivasi eksternal ke warga.

Selanjutnya, acara pentas seni dan kirab gunungan menjadi agenda penyemarak kegiatan rasulan, di mana warga bersama-sama mengiringi arak-arakan hasil panen (sayuran dan buah) ${ }^{16}$ ke balai desa, dengan dihibur acara pentas seni kebudayaan yang dipentaskan oleh para warga berupa pertunjukan wayang, tarian reog, dan jathilan pada puncak acara.

Adapun tradisi slametan atau kenduri dilaksanakan dengan membaca ayat suci al-Qur'an dan doa bersama. Pelaksanaan tradisi rasulan berbedabeda di setiap desa karena memiliki waktunya sendiri sendiri yang dihitung menurut kalender Jawa.

Pembacaan ayat suci al-Qur'an dan doa bersama dipimpin oleh pemuka agama dan tokoh adat kemudian diikuti oleh para warga berupa bacaan tahlil, surah pendek (al-Fatihah, al-Ikhlas, al-Falaq dan an-Naas) dan doa-doa ungkapan syukur kepada Allah swt.

${ }^{15}$ Gunungan artinya hasil panen berupa sayur-sayuran dan buah-buahan yang dibentuk seperti gunung (bukit) dan diarak-arak (kirab) oleh warga pada kegiatan tradisi rasulan bahkan adapula yang dibentuk gunungan-nya seperti sapi untuk diarak-arak dalam kegiatan tersebut.

${ }^{16}$ Hasil panen berupa sayuran dan buah yang beranekaragam, seperti: wortel, kacang, terong, tomat, padi, jagung, kacang panjang, dan cabai. 


\section{Nilai-nilai Pendidikan dalam Tradisi Rasulan}

\section{a. Bersih Dusun}

Bersih dusun merupakan kegiatan yang dilaksanakan oleh warga masyarakat untuk membersihkan lingkungan tempat tinggal bersama sama di masing-masing dusun sebelum puncak acara rasulan. Kegiatan ini dilakukan bertujuan untuk mempererat hubungan kekeluargaan sesama warga desa dalam lingkungan masyarakat.

Kegiatan ini selain ditujukan sebagai upaya mencintai lingkungan dan memelihara alam, juga ditujukan kepada pengembangan daya kolaborasi warga berupa nilai kerukunan, akrab, guyub dan gotongroyong. Hal ini seperti yang diungkapkan Bapak Karsino berikut:

"Dusun-dusun di Desa ini, kalau udah dekat rasulan ada juga mulai 4 bulan sebelum rasulan bersih-bersih dan gotong-royong bareng-bareng bersihin dukuh. Karena, jurinya itu ga ngasih tau mbak kapan mau dinilai, jadi eman-eman kita udah persiapkan jauh-jauh hari, biar dukuh kita juara. Tapi, yo utamanyakan bukan lomba dan juaranya sih mbak, yang penting warga rukun, akrab, dan mau gotong-royong untuk kepentingan bersama, pokoke guyub deh mbak." ${ }^{, 17}$

Kutipan di atas menunjukkan bahwa rangkaian kegiatan berupa "dusun bersih" memiliki nilai-nilai yang patut dilestarikan berupa rukun, akrtab, dan kerjasama antarwarga khususnya kepada anak-anak usia dasar melalui budaya dan kearifan lokal setempat. Sehingga, kekayaan budaya menjadi anugerah tersendiri bagi anak dalam bekalnya menuju sikap dewasa bermasyarakat.

\section{b. Kirab Gunungan}

Acara puncak dimeriahkan dengan kirab gunungan, maksud dari kirab gunungan yaitu seluruh warga masyarakat mengelilingi desa dengan membawa aneka gunungan dan atribut tambahan lain, sebagai contoh; "remaja putri membawa sapu, ibu-ibu mengenakan pakaian tani,

17 Wawancara dengan Bapak Karsino, warga Desa Selang Wonosari Kabupaten Gunungkidul Yogyakarta, pada tanggal 2 November 2019, pukul 11.14 WIB, di rumah beliau. 
remaja putra mengenakan pakaian prajurit zaman dahulu, bapak-bapak mengenakan pakaian tani dan membawa cangkul.”

Aneka gunungan yang dibawa mengelilingi desa berisikan hasilhasil panen berupa padi, kacang, jagung, terong, kangkung dan wortel. Kegiatan kirab ini dimaksudkan sebagai ucapan rasa syukur kepada Allah swt. yang telah memberikan hasil panen yang melimpah. ${ }^{18}$

Tradisi rasulan yang dilaksanakan di Kabupaten Gunungkidul jika dilihat berdasarkan pengaruh positifnya, maka tradisi tersebut selama ini selalu memberi pengaruh positif kepada masyarakatnya dalam menguatkan ikatan persauadaraan sesama warga masyarakat sehingga akan terwujud suatu masyarakat yang damai, kompak dan selalu rukun.

\section{c. Slametan}

Kegiatan selanjutnya yang dilakukan masyarakat di Kabupaten Gunungkidul yaitu slametan atau kenduri. Acara ini dilakukan di rumah kepala dukuh yang diikuti oleh seluruh warga laki laki di desa. Pelaksanaan kenduri dipimpin oleh seseorang yang dianggap pandai dalam agama dengan membaca doa-doa dan ayat-ayat suci alquran bersama-sama. Pada kegiatan slametan atau kenduri ini warga membawa nampah $^{19}$ yang diisi sego gurih atau nasi gurih berbentuk kerucut dan diberi Ingkung Ayam ${ }^{20}$. Ingkung ayam ini memiliki filosofi yang tidak bisa diabaikan dalam budaya Jawa. Ayam merupakan lambang rasa syukur yang didapat dari kenikmatan Allah swt. Ayam diletakan dalam kondisi utuh lalu dihias agar rapi dan indah.

\footnotetext{
${ }^{18}$ Erlangga Brahmanto, "Tradisi Rasulan Menjadi Andalan Etnik Tourism Kebupaten Gunungkidul Yogyakarta” Khasanah Ilmu $5 \quad$ (2), 2014 : 69-75. $\underline{\text { http://ejournal.bsi.ac.id/ejurnal/index.php/khasanah/article/download/506/399. }}$

${ }^{19}$ Nampah berarti semacam tempat makan.

${ }^{20}$ Lauk Ayam.
} 


\section{d. Pentas Seni (Wayang Kulit, Reog, Jathilan)}

Puncak acara rasulan dimeriahkan pula dengan acara-acara tambahan, yaitu wayang yang dilaksanakan pada malam hari. Acara ini masih tetap dilestarikan agar keragaman budaya Jawa tidak hilang. Selanjutnya Reog, acara tarian ini dilaksanakan pada siang hari bersamaan dengan acara jathilan. Acara-acara tambahan yang di laksanakan pada puncak tersebut berfungsi sebagai hiburan warga desa sekaligus tetap menjunjung tinggi budaya agar tetap dilestarikan bersama oleh warga.

\section{Nilai pendidikan dari kearifan lokal Desa Selang Kecamatan Wonosari Kabupaten Gunungkidul}

Prosesi pelaksanaan tradisi rasulan memiliki nilai-nilai pendidikan Islam yaitu; pertama niatan dan doa dalam tradisi rasulan ini kita hanya meminta kepada Allah swt., dan kedua bersedekah karena kita menyadari bahwa manusia membutuhkan bantuan dari orang lain, nilai kerukunan dan mempererat silaturahmi karena pada tradisi rasulan ada kegiatan doa besama kerabat dan tetangga. ${ }^{21}$

Hal senada disampaikan Bapak Karsino ketika diwawancarai:

"rasulan ini selain kita bersyukur atas rezeki berlimpah yang diberi Allah selama setahun, juga jadi ajang silaturahmi antarwarga, bahkan warga bisa 'bersedekah bumi' yang maksudnya sedekah bumi contohnya yang kita hasilkan atau panen selama satu tahun (nasi), terus sayuran dan buah." 22

Membaca ayat atau surat Alquran dalam tradisi rasulan. Ayat atau surat yang dibacakan beragam tergantung konteks acaranya. Surat-surat Alquran yang "pasti" dibacakan setiap tahunnya yaitu al-Ikhlas sampai anNaas. Tujuan pembacaan ayat-ayat ini adalah untuk mengagungkan kebesaran Allah swt.

21 Sami'un, “Tradisi Rasulan dalam Analisis Dakwah Islam di Desa Krawangsari Kecamatan Natar Lampung” Skripsi (Lampung: FITK UIN Raden Intan Lampung, 2017), h. 74.

22 Wawancara dengan Bapak Karsino, warga Desa Selang Wonosari Kabupaten Gunungkidul Yogyakarta, pada tanggal 2 November 2019, pukul 11.14 WIB, di rumah beliau. 
Membaca doa pada saat tradisi rasulan juga dilaksanakan dengan tujuan untuk memohon agar hidup selalu dalam bimbingan Allah swt., mengungkapkan rasa syukur kepada Allah swt., memperoleh petunjuk, dan perlindungan dari Allah swt.

Tradisi rasulan dalam pelaksanaannya secara tidak langsung memberi contoh untuk selalu bersyukur kepada Allah, karena doa-doa yang dituju dalam tradisi rasulan hanya kepada Allah, dengan membaca ayat atau surat surat alquran dan tahlil dengan harapan semoga hasil panen menjadi keberkahan bagi seluruh warga.

Tradisi rasulan juga memiliki nilai-nilai dalam hal pendidikan untuk mengajarkan manusia agar menjadi lebih baik lagi. Dalam hal pendidikan, tradisi rasulan terdapat nilai nilai pendidikan keimanan (akidah) dan pendidikan akhlak.

\section{a. Pendidikan Akidah}

Tradisi rasulan memiliki nilai-nilai ajaran Islam berupa ajakan mengagungkan kebesaran Allah swt. uraiannya sebagai berikut:

a. Upaya memupuk rasa keyakinan kepada Allah swt. dengan mengucap rasa syukur atas rezeki yang diberikan-Nya,

b. Mengingat Allah swt. melalui slametan berupa doa, tahlil dan zikir.

\section{b. Pendidikan Akhlak}

Nilai pendidikan akhlak dalam tradisi rasulan yakni menjadi momentum sekaligus wadah bagi masyarakat menjalin komunikasi kekuatan, alam, dan sosial. Sebagai umat manusia kita wajib untuk melakukan interaksi dengan sesama manusia, lingkungan maupun dengan Allah SWT. Jadi etika dan prilaku masyarakat dapat terlihat dalam kegiatan kegiatan di tradisi rasulan. ${ }^{23}$

c. terdapat nilai sodaqoh, di mana setiap warga akan memberikan makanan kepada kerabat atau masyarakat setempat

${ }^{23}$ Erni Ningsih, "Nilai Nilai Pendidikan Islam Dalam Tradisi Rasulan Di Desa Giriloyo, Wukirsari, Imogiri, Bantul” Skripsi (Yogyakarta: FITK UIN Sunan Kalijaga Yogyakarta, 2012), h. 115 . 
d. Terdapat nilai silarurahmi karena saat tradisi rasulan berlangsung akan dijadikan ajang untuk berkumpul dan menambah keakraban.

e. Terdapat nilai keikhlasan karena akan tertanamkan pada diri seseorang bahwa dirinya melaksanakan tradisi rasulan menjadi agar bermanfaat dan menjadi berkah kebaikan, mengajarkan seseorang untuk selalu bersyukur kepada Allah swt., mengajarkan agar selalu memohon dan berdoa hanya kepada Allah swt.

\section{KESIMPULAN}

Masyarakat Desa Selang Kecamatan Wonosari Kabupaten Gunungkidul memiliki sebuah budaya yang sejak zaman dahulu hingga sekarang masih dilestarikan dan semakin disesuaikan dengan keadaan masyarakat saat ini, tradisi tersebut adalah rasulan. Di dalam tradisi rasulan terdapat kegiatan bersih dusun, kirab gunungan, slametan dan pentas seni. Adapun nilai-nilai keislaman dalam tradisi tersebut secara garis besar meliputi nilai pendidikan akidah dan pendidikan akhlak. Nilai pendidikan akidah mencakup (1) memupuk rasa keyakinan kepada Allah swt. dengan mengucap rasa syukur, (2) mengingat Allah swt. melalui slametan berupa doa, tahlil dan zikir. Sedangkan nilai pendidikan akhlak mencakup (1) nilai keikhlasan, (2) solidaritas, silaturahmi dan keharmonisan antarwarga, (3) saling berbagi melalui sedekah "bumi” dan makanan antarwarga.

\section{DAFTAR PUSTAKA}

Anggraini, Bea. (2012). "Faktor-faktor Penanda Kesantunan Tuturan Imperatif dalam Bahasa Jawa Dialek Surabaya: Analisis Pragmatik" Humaniora 17 (1). 67-77. https://journal.ugm.ac.id/jurnal-humaniora/article/view/829.

Brahmanto, Erlangga. (2014). "Tradisi Rasulan Menjadi Andalan Etnik Tourism Kebupaten Gunungkidul Yogyakarta" Khasanah Ilmu 5 (2): 69-75. http://ejournal.bsi.ac.id/ejurnal/index.php/khasanah/article/download/506/39 Chakim, Sulkhan. (2015). "Potret Islam Sinkretisme: Praktik Ritual Kejawen?"

Komunika: Jurnal Dakwah dan Komunikasi 3 (1): 1-9. http://ejournal.iainpurwokerto.ac.id/index.php/komunika/article/view/110/84. 
Darmojo, Kuntadi Wasi. (2019) "Eksistensi Keris Jawa dalam Kajian Budaya" Texture: Art \& Culture Journal 2 (1): 49-60. https://jurnal.isiska.ac.id/index.php/TXT/article/view/2630/2378.

Fuadhiyah, Ucik. (2011). "Simbol dan Makna Kebangsaan dalam Lirik Lagu-lagu Dolanan di Jawa Tengah dan Implementasinya dalam Dunia Pendidikan" Lingua: Jurnal Bahasa dan Sastra 7 (1): 15-26. http://journal.unnes.ac.id/nju/index.php/lingua/article/download/865/798.

Isfironi, Muhammad. (2013). "Agama dan Solidaritas Sosial: Tafsir Antropologi Terhadap Tradisi Rasulan Masyarakat Gunungkidul DIY” Al-'Adalah 16 (2). http://ejournal.iain-jember.ac.id/index.php/aladalah/article/view/162/138.

Marzuki. (__ _ _ " Tradisi Dan Budaya Masyarakat Jawa Dalam Prespektif Islam” Makalah, (Yogyakarta: Universitas Negeri Yogyakarta), h. 1-13. http://staffnew.uny.ac.id/upload/132001803/lainlain/Dr.+Marzuki,+M.Ag_.+ $\underline{\text { Tradisi }+ \text { dan+Budaya }+ \text { Masyarakat }+ \text { Jawa }+ \text { dalam+Perspektif }+ \text { Islam.pdf. }}$

Ningsih, Erni. (2012). "Nilai Nilai Pendidikan Islam Dalam Tradisi Rasulan Di Desa Giriloyo, Wukirsari, Imogiri, Bantul” Skripsi (Yogyakarta: FITK UIN Sunan Kalijaga Yogyakarta).

Ridwan H, Muhammad. dkk. (2019). "Kajian Empiris Kuliah Kerja Nyata (KKN) UIN Sunan Kalijaga Terhadap Nilai Kearifan Lokal Tradisi Rasulan Gunungkidul” Prosiding Konferensi Pengabdian Masyarakat 1 (1): 113-115. https://jurnal.uns.ac.id/habitus/article/view/20416/15846.

Rinasari. (2012). “Aspek Pendidikan Nilai Religius dalam Tradisi Rasulan (Studi Kasus di Dukuh Ngadipiro Desa Grajegan Kecamatan Tawangsari Kabupaten $\begin{array}{llll}\text { Sukoharjo)" } & \text { Skripsi } & \text { (Solo: } & \text { FKIP }\end{array}$ http://eprints.ums.ac.id/21066/14/11. Naskah_Publikasi.pdf.

Sami’un. (2017). "Tradisi Rasulan dalam Analisis Dakwah Islam di Desa Krawangsari Kecamatan Natar Lampung" Skripsi (Lampung: FITK UIN Raden Intan Lampung).

Sartini, Ni Wayan. (2009). "Menggali Nilai Kearifan Lokal Budaya Jawa Lewat Ungkapan (Bebasan, Saloka, dan Paribasa)" Logat: Jurnal Ilmiah Bahasa dan Sastra 5 (1): 28-37. 
http://www.academia.edu/download/33900290/Bahasa_dan_Sastra_Logat

Vol 5 No 1 April 2009.pdf\#page $=30$.

Siswanto, Nurhadi. (2012). "Metafisika Simbol Keris Jawa" Jurnal Filsafat 22

(1). https://journal.ugm.ac.id/wisdom/article/view/12986/9257.

Syarifuddin, Didin. (2016). "Nilai Wisata Budaya Seni Pertunjukan Saung Angklung Udjo Kota Bandung Jawa Barat Indonesia" Jurnal Manajemen dan

$\begin{array}{lllll}\text { Resort \& } \quad \text { Leisure } & 13 & \text { (2). }\end{array}$

https://ejournal.upi.edu/index.php/jurel/article/view/4979.

Wulandari, Erviana. (2018) "Penguatan Nilai Budi Pekerti Melalui Tradisi Rasulan Gunungkidul" Habitus: Jurnal Pendidikan, Sosiologi, dan $\begin{array}{llll}\text { Antropologi } & 2 & \text { (1): }\end{array}$ https://jurnal.uns.ac.id/habitus/article/view/20416/15846. 